palate) was $35 \%$ vs. $0 \%$ ( $p<0.0005)$. Gingival recessions were $42.5 \%$ vs. $2.5 \%$ ( $\mathrm{p}<0.0005$ ). Oral mucosal involvements (via clinical examination of regions in the oral cavity) including mucosal atrophy and thinning were seen more frequently in Scl than in normal controls $(\mathrm{p}<0.0005)$. The same was true for mucosal pallor $(\mathrm{p}=0.002)$, mucosal telangiectasia $(\mathrm{p}<$ $0.0005)$, mucosal erosions and ulcerations $(\mathrm{p}=0.002)$.

Conclusion Systemic sclerosis frequently involves different parts of the oral cavity. The teeth, tongue, gengiva and mucosal folds involvement were seen more than normal population. We recommend oral examination regularly in patients with scleroderma.

\section{FRI0104 REACTIVE ARTHRITIS IN 43 IRANIAN PATIENTS}

AR Jamshidi, F Gharibdoost, M Akbarian, F Shahram, A Nadji, F Davatchi. Rheumatology Research Center, Shariati Hospital, Tehran, Iran

10.1136/annrheumdis-2001.139

Background Reactive arthritis refers to an acute non-purulent arthritis reactive to an infection elsewhere in the body.

Objectives The aim of this study was to find the demography of reactive arthritis in Iranian patients.

Methods In a five years period 43 patients who definitely were diagnosed as Reactive Arthritis were seen in our centre. All patients were classified by the European Criteria for reactive arthritis classification. 139 items were checked in every patient. The data were analysed by SPSS software.

Results The age ratio was $17-45$ years with a mean age of 23.8 years. Forty patients (93\%) were male and the male to female ratio was 13/1. A history of infection in 1 to 4 weeks before the attack of reactive arthritis was diarrhoea in 20 (46.5\%) and urethritis in 16 patients (37.2\%).

The clinical manifestation during the disease were: constitutional symptoms in 24 (55.8\%), including fever 44.2\%, weight loss $32.6 \%$, fatigue $20.9 \%$, lower extremity arthritis $100 \%$, and upper extremity arthritis $48.8 \%$. Sacroiliac involvement was seen in $37.2 \%$ of patients. The most common peripheral arthritis was seen in ankle (83.7\%) and knee joints (76.7\%). Achilles and Calcaneal Enthesopathy were seen in $46.5 \%$ of patients. Extra articular manifestations were seen in 37 patients (86\%): eye involvement in 31 patients $(55.8 \%)$ and mucocutaneous involvement in 13 patients (30.2\%).

Lab test: Leucocytosis were seen in $23.2 \%$, Anaemia in $11.7 \%$, Erythrocyte sedimentation rate $>50$ in $62.5 \%$, positive CRP in $83.7 \%$ and positive HLA-B27 in $46.8 \%$ of cases.

Conclusion Reactive Arthritis in Iranian patients has the same clinical manifestations as in other countries. Male to female ratio in the Iranian patient is more than in other countries. HLA-B27 is less common in Iranian patients than in other countries.

\section{FRI0105 PREVALENCE OF THYROID DISORDERS IN SYSTEMIC LUPUS ERYTHEMATOSUS: A STUDY IN 100 BRAZILIAN PATIENTS}

AM Kakehasi, VN Dias, JE Duarte, CC Lanna, MA Carvalho. Rheumatology Unit, Hospital Das Clínicas, Belo Horizonte, Brazil

10.1136/annrheumdis-2001.140
Background The association of thyroid dysfunction with autoimmune diseases is well known, however its prevalence in patients with systemic lupus erythematosus (SLE) is not well established. Objectives The objective of this study was to determine the prevalence of thyroid disorders in 100 Brazilian lupus patients, including laboratorial and clinical manifestations suggesting thyroid abnormalities and its possible relation with lupus activity.

Methods We evaluated 100 Brazilian patients, 93 females and 7 males, with mean age of 34,2 years. All of them had the diagnosis of SLE, according to the criteria of the American College of Rheumatology, and did not had a previous history of thyroid disease.

Results Laboratory findings of thyroid dysfunction were found in sixteen $(16 \%)$ patients. In nine patients $(9 \%)$ the exams indicated subclinical hypothyroidism, in two patients $(2 \%)$ the results were compatible with subclinical hyperthyroidism and in four patients (4\%), primary hypothyroidism was diagnosed. One patient had the level of free thyroxin (T4 1) below the normal range. Positive anti-thyroid auto-antibodies was found in six patients $(6 \%)$, being anti-peroxidase in four patients $(4 \%)$, antithyroglobulin in one patient $(1 \%)$ and both in one patient $(1 \%)$. The diagnosis of concomitant hypothyroidism was confirmed in only one patient who presented positive anti-peroxidase antibodies. Seventy-six patients $(76 \%)$ reported clinical complaints suggestive of thyroid dysfunction, such as: emotional liability, anxiety, weight loss, increased appetite, fatigue and astenia. The evaluation of activity criteria, based on the SLEDAI (Systemic Lupus Erythematosus Disease Activity Index), did not show statistically significant difference between the groups with and without alterations of the thyroid function (7,44 and 5,26 respectively).

Conclusion The authors conclude that thyroid disorder, especially the subclinical form, is a frequent finding in patients with SLE. However, they emphasise that, based on the results of the studied group, positive laboratory findings of thyroid dysfunction are not related to the activity of lupus disease.

\section{REFERENCES}

1 Miller FW, Moore GF, Weintraub BD, Steinberg AD. Prevalence of thyroid disease and abnormal thyroid function test results in patients with systemic lupus erythematosus. Arthritis Rheum. 1987;30:1120-31

2 Tsai RT, Chang TC, Wang CR, Chuang CY, Chen CY. Thyroid disorders in chinese patients with systemic lupus erythematosus. Rheumatol Int. 1993;13:9-13

3 Vianna JL, Haga HJ, Asherson RA, Swana G, Hughes GRV. A prospective evaluation of antithyroid antibody prevalence in 100 patients with systemic lupus erythematosus. J Rheumatol. 1991;18:1193-5

4 Weetman AP, Walport MJ. The association of auto-immune thyroiditis with systemic lupus erythematosus. Br J Rheumatol. 1987;26(5):359-61

\section{FRI0106 THE ASSESSMENT OF GLOMERULAR FILTRATON RATE DURING THE TREATMENT OF PATIENTS WITH LUPUS NEPHRITIS}

${ }^{1} \mathrm{H}$ Seleskovic, ${ }^{1} \mathrm{~S}$ Mulic, ${ }^{2} \mathrm{~N}$ Kapidzic Basic, ${ }^{3} \mathrm{M}$ Hukic, ${ }^{4} \mathrm{~A}$ Cickusic, ${ }^{5} \mathrm{M}$ Smajic. ${ }^{1}$ Rheumatology Department, Internal Clinic, ${ }^{2}$ Clinic for Physical Medicine and Rehabilitation; ${ }^{3}$ Microbiology Department, University Clinical Center, Tuzla, Bosnia \& Herzegovina; ${ }^{4}$ Nuclear Department, Internal Clinic; 5 Internal Clinic

10.1136/annrheumdis-2001.141

Background The deterioration of renal function is one of the most important prognostic predictors in lupus nephritis (LN). Objectives To determine glomerular filtration rate (GFR) in patients (pts) with LN and to clarify the characteristics of renal haemodynamics during the treatment of $\mathrm{LN}$. 